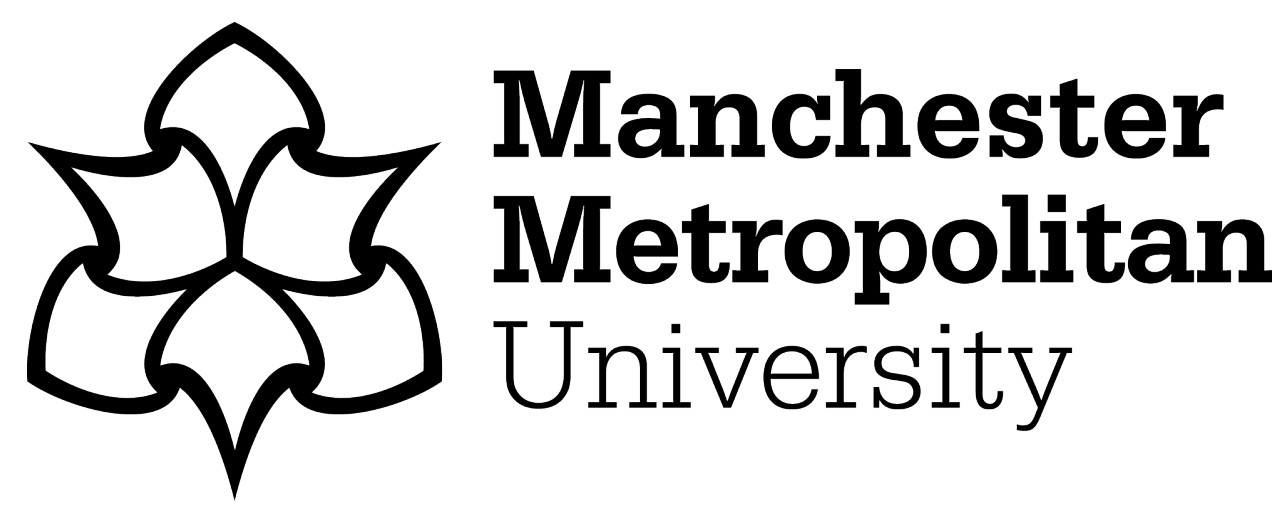

Hammersley-Fletcher, LJ ORCID logoORCID: https://orcid.org/0000-00024443-6856, Wingrove, D, Chester, A and Clarke, A (2017) Leading Developmental Peer Observation of Teaching in Higher Education: Perspectives from Australia and England. British Journal of Educational Studies, 66 (3). pp. 365-381. ISSN 0007-1005

Downloaded from: https://e-space.mmu.ac.uk/618524/

Version: Accepted Version

Publisher: Taylor \& Francis (Routledge)

DOI: https://doi.org/10.1080/00071005.2017.1336201

Please cite the published version 


\title{
Leading developmental peer observation of teaching in Higher Education: perspectives from Australia and England
}

\begin{abstract}
Whilst peer observation of teaching is well established as a practice that can enhance teaching quality, the challenge to fully embed this practice in universities remains unresolved. This article analyses the perspectives of eighteen university leaders (nine Australian and nine English) drawn from a range of school-based leaders to senior leaders of learning and teaching. Our study indicates that some of the challenges associated with leading such schemes can be mitigated through approaches to educational leadership that enact a respectful and collegiate ethos. This we suggest can support developmental academic engagement in peer observation for positive and lasting change.
\end{abstract}

Key words: peer observation of teaching; peer feedback; peer review; leadership

\section{Introduction}

Over the past decade the imperative to enhance teaching quality has gained prominence within both the Australian and English tertiary sectors. The growing focus on teaching quality and improving the student experience has been paralleled by the increased focus on institutional metrics and the professionalisation of tertiary teaching (Henard and Roseveare, 2012). It is within such a climate that we have seen the emergence of peer observation of teaching (POT) and its pivotal role in quality assurance and quality enhancement systems. O'Leary suggests that continuous improvement and quality have become 'the mantra' of further education policy ( $p$. 697) and POT sits at the coal-face of teacher professional development. What constitutes professional development in further education and how this is undertaken, however, remains a contentious issue (O’Leary, 2013).

In Australia and England, universities are challenged to professionalise tertiary teaching in ways that serve and reflect both institutional missions and the converging needs of industry and Government. Tensions between quality reform agendas and the autonomous professional learning needs of academics converge. Paradoxically, quality as compliance has been privileged over quality as learning about 'how we can do better towards achieving our purpose' (Houston 2007, p. 69).

In this paper, we identify core principles that are essential to fostering meaningful engagement in POT. We grapple with issues and tensions inherent within a scheme that on the one hand, is envisioned as a supportive process involving the sharing of professional knowledge and experiences, and on the other is enacted as a performative quality indicator. Tensions arise because performance driven agendas commonly create a culture of surveillance, undermining academic freedom and agency (O'Leary, 2013; Skelton, 2012).

The key issues associated with POT such as 'a managerial vs. collegiate process, an evaluative mechanism vs. a collaborative experience and an imposed vs. voluntary practice' remain the subject of debate (Carroll \& O'Loughlin, 2014, p. 447). To contribute to this debate we discuss the complexities of embedding developmental 
POT and recommend enacting POT as a developmental process by actioning guiding principles that foster professional cultures of trust, respect and collegiality.

\section{Peer observation of teaching}

Gosling (2014) suggests POT can be classified as 'evaluative', 'developmental' or 'collaborative'. These classifications represent distinct principles, practices and processes. Across the spectrum of POT there are significant challenges that can undermine the potential of the process to deliver needs-based professional development for continuous improvement.

These challenges are underscored by the prevailing tension between the converging agendas of quality assurance versus quality enhancement (Bell, 2005; Bell and Mladenovic, 2008; Donnelley, 2007; Gosling, 2005). Researchers highlight that an emphasis on the institutional imperative for quality assurance undermines sustained and meaningful engagement in POT (Gosling 2014; Lomas and Nicholls 2005; Peel, 2005). When framed as a mechanism for quality measurement, POT can be viewed, experienced and resisted by educators who perceive such a process as a means of ensuring compliance with a purely managerial agenda (Peel, 2005).

When framed as a developmental process, benefits have been noted in the integration of theory and practice and as an outlet for teachers to discuss their teaching (Donnelly 2007). Developmental POT can enhance teaching practice by encouraging critical self-reflection (Carroll and O'Loughlin 2014; Chester, 2012; Hammersley-Fletcher and Orsmond 2004; Peel, 2005), creating opportunities for teaching staff to become more aware of student experiences, and enabling groups to identify and disseminate good practice (Gosling, 2002).

Developmental POT schemes recognise the heterogeneous, contested and contradictory production of 'academic cultures' through the process of learning and teaching (Trowler and Knight, 2000). However, developmental POT schemes, as Lomas and Nicholls identify, require 'consensual leadership and skilled management ... to gain the confidence and the support of academic staff' (2006, p. 8). Leadership of developmental POT is therefore the focus of this paper.

\section{The role of academic leadership}

While research evaluating the impact of POT programmes continues to expand (Lomas and Nicholls, 2005), a gap exists in knowledge about how to effectively lead such models. We seek to help fill that gap by identifying the factors that contribute to the successful and sustainable leadership in this area. We examine the leadership of this activity across two distinct university contexts, Australia and England. The aim is to establish guiding principles for leadership of POT that transcend educational contexts.

In the Australian case, a model of voluntary, reciprocal developmental peer observation (Peer Partnerships) was in its third year of implementation at a large urban university. The Peer Partnerships model is underpinned by best practice principles in adult professional learning defined by Speck (2002). The model has to date been successful in uptake and in delivering professional learning outcomes for teaching staff. At the time this research was conducted there were more than 300 volunteer peer partners and 27 school-based leaders. At the time of publication 
participant numbers had grown to over 500 volunteer educators. The Australian university was chosen as the authors developed and co-lead Peer Partnerships at this institution. Whilst Peer Partnerships was relatively well established within the university the challenge to fully embed and sustain this practice in the wider institutional culture was yet to be fully resolved.

In the English case, a model of POT (Peer Review) for developmental purposes was emerging with inconsistent uptake. The English university was chosen because it was at a critical point in seeking to embed Peer Review more widely across the university in negotiation with staff although this position shifted as the research progressed towards a more top-down approach in terms of its guiding principles. As the research period was drawing to a close, some of the staff consultation team were replaced and the emphasis shifted to a greater focus on how to make POT work with less focus on what staff wanted from the process. The rationale behind this was based on urgent external requirements to demonstrate that Peer Review was taking place.

Taking account of institutional cultural differences, the two universities in this study provide unique perspectives in which the processes of embedding POT can be systematically explored. The case studies include conceptions of POT; leading POT; and the extent to which POT has been implemented and embedded in the university culture. The questions guiding this research were: What leadership challenges and opportunities arise in seeking to embed developmental POT in the university culture? What should this leadership approach look like?

\section{Method}

\section{Approach to data collection}

We focused on the perspectives of nine leaders from an Australian university (four women, five men) and nine leaders from an English university (five women, four men) who held teaching and learning positions in their respective universities. In each context we had two categories of leader. The first category referred to as senior leaders includes Deans/ Heads of School/Faculty and Deputy Heads of School/Faculty, Teaching and Learning. The second category is a group we refer to as school-based leaders, which includes leaders with responsibility for running learning and teaching developments in schools/faculties.

Semi-structured interviews were conducted to elicit rich data, capture participants' perspectives and to 'understand the world as seen by the respondents' (Patton 2002, p. 21). Interviews were designed to assure confidentiality, reflect contextual complexities, capture the uniqueness of practice and 'get closer to minds' (Hodder, 1994, p. 384). The sample was purposefully selected to provide insight into the phenomena being investigated (Patton, 2002). In the Australian context, participants were selected on the basis that they occupied middle to senior learning and teaching academic management positions within the institution, and because in undertaking these roles they had experienced either a previous engagement with Peer Partnerships through co-leading and/or supporting its implementation within their particular or the broader university context. Hence, they could offer experiential insights into the leadership challenges and opportunities that embedding Peer Partnerships more fully in the institutional culture can present. 
Likewise in the English context participants were selected because they occupied middle to senior learning and teaching academic management positions within the institution. In this context staff were involved in supporting the development of new approaches to POT practice. Participants represented varied disciplinary and organisational contexts as well as varied individual backgrounds, career levels, experience, values and aspirations.

Interview themes were outlined in the initial contact with each leader. A research assistant, unknown to the interviewees, conducted semi-structured interviews of 30-40 minutes duration. This approach allowed leaders to be as free as possible to talk about the strengths, limitations and the complexities of their experiences, and took into consideration the tensions associated with conducting insider research. Hanson (2013) identifies important tensions to be acknowledged and addressed in conducting insider research. These tensions include proximity to participants, the negotiation of multiple roles, internal politics, ethics and voice. To ensure confidentiality we have removed or changed information that might allow participants to be identified. Psuedonyms are used.

We adopted an analytical approach, conducting comparisons across answers using the six-phase process outlined by Braun and Clarke (2006), including an iterative cycle of identification, analysis and review. We cross-referenced identified themes through sharing interview transcripts amongst the authors and undertaking an independent analysis before making comparisons.

\section{Findings}

Four themes emerged from our study that confirmed and advanced the issues identified in the literature. Comparisons between Australia (AU) and England (EN) underscore the importance of cultural and contextual understandings in relation to sustainable practices. These themes relate to:

- Clarifying conceptions of peer observation

- Garnering academic 'buy-in'

- Managing challenges and tensions

- Securing institutional support

\section{Clarifying conceptions of peer observation}

Respondents' conceptions of POT ranged from POT for developmental purposes through to POT for quality assurance and performance management. As AU senior leader Don identified, historically POT was used as 'a blunt form of performance management'. The legacy of such practices and 'antagonistic management' can provoke resistance. If the intent of POT is developmental this needs to be made explicit. For example, AU leader Sarah noted that POT was understood as a process distinct from mentoring, with the notion of the 'expert reviewer' contested. She described the formative developmental nature of Peer Partnerships as enabling an exchange of practice that was reciprocal. This idea was confirmed by AU leader Bill who said that developmental POT provided a 'way of valuing teaching and providing opportunities for colleagues to debrief'.

AU senior leader Greg defined POT as an umbrella term that encompassed a voluntary, reciprocal process, and a summative review process. He highlighted the 
need to ensure that their distinctive purposes are clearly articulated and understood by leadership and the wider academy. This presents a challenge in the large tertiary institution because discourses of performativity can undermine the developmental intent of POT focused on continuous improvement and academic agency.

In the UK, POT was subject to a number of underlying assumptions. A significant number of staff viewed POT with suspicion seeing the process as one which management could use to monitor staff performance (not unlike that described by AU Senior Leader Don above). Such suspicions were echoed by the unions who emphasised the voluntary nature of this process and explained that no individual should be pressured into taking part in POT. Others viewed POT as an opportunity to work with colleagues to discuss and improve teaching and learning: 'we in the Faculty see it as a peer support for teaching as in a developmental context' (EN school-based leader Debbie).

Further, the central University administration took an interest in promoting POT by identifying a cross-faculty team to develop and then operationalize the process of POT. Some members of this team were interviewed for this project. Consequently respondents included those who held some doubts about POT processes but nevertheless were committed to embedding a process of POT that they perceived would benefit colleagues and the University. At the time of collecting data, the recommendations of this committee were being re-formulated centrally by the University to go back to a newly formed committee.

\section{Garnering academic 'buy-in'}

Responses highlighted the need to emphasise the value of POT to garner academic 'buy-in'. All respondents recognised that the main challenge of leading and implementing POT is 'convincing academics' that this activity is worth their while and that it is a positive and rewarding form of professional development. Most leaders recognised that part of their leadership role was to engage in processes of 'changing perceptions', 'highlighting benefits' and challenging the notion that teaching is a 'private' activity. EN school-based leader Margaret argued she had to be 'the convert that goes out and spreads the gospel out in the faculties'. Whilst AU school-based leader Ros noted that the second round of implementation was 'easier to promote' [because] if other teachers have said 'oh yeah... it was good for me'...that's how we get our next participants...in fact now people are coming to us'.

There did however, appear to be greater tension expressed in the data from England. EN senior leader Jack raised questions about the need to address the difference between peer review in research and peer observation in teaching saying, 'people are ... used to their performance in research being measured ... but [in] the teaching arena they all get worried about it'. EN senior leader Joan was also concerned that when applied to teaching this process became threatening saying, "peer observation... is an area that staff are very frightened of... it's always seen ... as a tool with a big stick...'.

All respondents saw the benefits of POT if handled well; it was understood as having the potential referred to by Boud (2001) for learning through sharing. All leaders believed that any POT programme should be guided by the notion of continuous development of practice. As AU senior leader Don said, 'teaching is a profession in 
need of celebration, renewal and continual review'. In both universities leaders considered that POT as a positive process that could enhance the professionalisation of teaching in higher education through reflective practice. AU school-based leader Bill argued that POT allowed for a 'more conscious, more alert, more sensitive' approach to teaching.

EN school-based leader Margaret reasoned that the process should 'demonstrate that it isn't managerial observation, that it is something non-threatening and something beneficial'. Likewise AU senior leader Viv said 'teachers need to be guaranteed that they are not being judged or penalized by their managers'. AU school-based leader Alison agreed saying that staff should not feel they are 'being put under the microscope, there's no judgement'. The key issue for AU senior leader Greg is to be clear about the aim of the process, explain this to all so that they understand what they are engaging in and ensure that the process does what is wanted.

Ownership, for AU school-based leaders Ros and Alison, was 'critical' to gaining academic 'buy-in'. A tension emerged in the interviews between the extent to which a programme of POT could be owned rather than imposed whilst at the same time arguing that all would benefit from engaging. There was ambivalence amongst the respondents from the English university about the degree to which staff should be compelled to engage in the process. Clearly, any new process needs to be positive for both the participants and the institution so that both gain benefit balancing the time and effort needed to engage and make it work.

\section{Managing challenges and tensions}

A key challenge raised by staff at both universities was an expressed need for clarity around the terminology used to describe POT. Whilst two processes of POT exist in the Australian university, Peer Partnerships for developmental purposes and Peer Review for promotion purposes, the boundaries between these were often blurred, with institutional intent needing to be transparent, purposeful and owned by all levels of leadership. AU leaders were attracted to the use of the overarching term 'Peer Feedback' that allowed for formative and summative processes to co-exist.

There was more disparity in the responses from EN leaders ranging from those who thought the language was incidental, through to those who had negative associations with particular terms. For example EN school-based leader Angus felt that 'peer observation... [was] negative ... or a deficit'. Likewise EN senior leader Louise felt that POT 'gets linked with performance rather than enhancement more often than not'.

Senior EN leaders all identified tensions around setting boundaries for the process of observation. Whilst they talked about the need for confidence in the system and the levels of trust necessary, some did see benefits with connecting POT with systems of appraisal by engaging in the monitoring perspective highlighted by Blackmore (2005). For these respondents a lack of progress over time might therefore be identified and managed. The majority of EN respondents however vehemently disagreed with this approach. One EN school-based leader (Kerry) argued, 'people are precious, confidentiality is of prime importance in enabling staff to develop with no sense of any threat in admitting a need to improve aspects of practice'. 
This tension was evident in EN school-based leader Angus' response. He was sceptical about how institutions would tie various aspects of observation together, arguing that such processes can get turned into a scheme in ways that deter engagement. Knights and McCabe (2000) argue that the more bureaucratic processes become the less staff will want to engage. EN senior leader Louise expressed concerns about these complexities adding that she wasn't quite sure where she positioned herself in this debate.

I think there are some supreme challenges ahead because if we're saying that to get a universal enhancement model with very high levels of buy in, it's got to be separated from a performance review model... I would want to be able to promote people or to reward people in some way for demonstrating excellence in teaching. If you do that then you instantly get into the notion of ... well, there's the other end of the spectrum where you've got to penalise people who aren't up to scratch... I'm not sure about boundaries.

EN school-based leader Margaret argued that it was worrying to hear that some staff had never engaged in being observed. She stated that once they have been 'forced' to engage with the process they then find its benefits and 'carry on engaging'. This raised a further dilemma about the various benefits of mandatory versus voluntary engagement. EN school-based leader Joan emphasised what she saw as the 'stark reality' of the clear link between student experience and academic jobs,

we don't want people that...don't bother doing the best they possibly can do for our students, because without our students none of us have a job.

Joan's statement implies that poor teaching leads to student attrition because if students are not engaged they leave. Joan believed that academics had a duty to themselves and course colleagues to keep their practices up to date and be open to a review process as there were institutional narratives about courses closing because students opt out of their programmes of study.

EN school-based leader Kerry was concerned to enhance engagement through celebrating good practice rather than annoying people through compulsion, being judgemental or through using a misinformed translation of feedback data as a weapon to criticise staff performance. These arguments expose the tensions and disagreements around what Henard and Roseveare (2012) describe as the notion of continuous improvement leading to improved student outcomes.

Amongst AU senior leaders there was an awareness of the detrimental socio-political history of classroom review. AU senior leader Don noted the 'legacy of what used to happen with teachers in the post-war era'. This style of review was 'punitive and structured antagonistically' which the unions have 'resisted heavily'. For this leader, the history of classroom review shaped a current focus on developmental professional relationships rather than the 'adversarial relationships' of the past. This is interesting when compared to the perceptions in England where almost the opposite is argued. 
In England, the growing narrative since Thatcher came to political power in 1979 has been around the need to monitor and assess educational delivery to ensure that work is of a good standard and not failing those they educate. The underlying assumption here suggests accountability measures are effective mechanisms for the control of educators. As EN school-based leader Angus explained, 'if you look at schools and you look at further education colleges ...they're inspected quite a lot ... and it's an idea to make certain that you fit the purpose'. For some, this has lead to a fear and defensiveness around practice that mediates against educators sharing openly and honestly both their successes and their failures as Skelton (2012) has argued.

AU senior leader Greg noted that peer feedback is often not 'taken seriously by promotion committees' because it has not been a 'scholarly process' or a widely accepted part of 'professional teaching practice'. Greg added that formalising the process and framing it in the light of established sector-wide 'dimensions of effective teaching' is a way of building the 'prestige' of the professional activity and 'raising the status', through positive reinforcement, of those engaged in and leading the programs. This links again to the tensions expressed by EN senior leader Louise earlier around using peer feedback as a basis for promotion.

Notably leaders at the Australian university were predominantly more positive about the alignment between POT and systems of rewards and recognition than those in England where there was a much higher level of scepticism and even antagonism to what they perceived as accountability agendas.

\section{Securing institutional support}

The importance of securing institutional support was a key issue for both organisations. In Australia a voluntary approach had supported the successful implementation of POT. There was general agreement that bottom-up integration at a school level was vital for the ongoing success of the program. In contrast the English institution had introduced the notion of POT but take-up in departments was patchy. Consequently, they moved to engage representatives from across the University in leading roles to secure a better way forward. During this process however, the university senior management decided that a more directive approach would be helpful to get the process underway. Consequently, many of the responses during the EN interviews adopted varied positions in relation to compulsion and voluntary engagement as discussed in the previous sections.

In both cases Heads of Schools/Faculties were seen to be crucial to success. As one senior leader commented,

[if] a Head of School... takes ownership of the Peer Partnership program for their school [this helps staff] realise that it's being taken seriously. (AU senior leader Greg)

AU school-based leader Daniel echoed this by noting the Head's approval was 'a small but very significant measure of support. It attracted others to participate because it was official. It validated the project'. EN senior leader Jack appeared to agree with this but also suggested, 'we need... different ways of doing it across whatever faculty, school, and division'. 
Time to undertake POT work was raised by over half of the respondents from England who also referred to workloads and constant pressure. Respondents from the Australian university highlighted that whilst cultural change could be self-sustaining, they recognised that one of the biggest challenges for widespread uptake of POT remained tied to the workload of participants. As AU school-based leader Bill commented:

there's just the complexity of finding time for people who are being pressed in three areas. They have to do teaching, they have to do some degree of admin, and then they have to supposedly be research active. Not many people have much time for anything else.

AU senior leader Greg noted how important is to 'change the perception around this, in that it's not extra work, it's actually just part of professional development'. Likewise AU school-based leader Bill said 'if they've been formally allocated some time then they will realise it's being valued and recognised'.

Several AU leaders noted integrating Peer Partnerships into work-plans created time for engagement, emphasised accountability and signalled the value of teaching. Senior leaders understood that change involves addressing the issues of workload and time. This was an indicator of underlying institutional good-will and required resourcing. In England different Schools/Faculties had taken individual approaches to providing opportunities for POT with only one offering a discrete allocation of time on the timetable, others finding this more difficult to finance. In England moreover, financial constraints are becoming ever more apparent and all sectors of education are watching their budgets very carefully. Thus, whilst the will to support staff might be apparent, there is little financial flexibility to facilitate staff with extra time. For initiatives to be acted upon this often requires careful planning around how this can be done within the hours already committed. Shortland suggests that this is an indicator of the underlying motivation of the institution around peer feedback (Shortland, 2004). Without resourcing POT is not seen as valued.

In England there was a divide about whether training was necessary. For those who thought it important there were additional variations about whether just some people were trained and the information cascaded down to all or whether all should be involved directly in the training process. There was also an acknowledgment that this would have substantial resource implications. A related issue was raised in the Australian university in relation to the role of leaders. Three AU school-based leaders, who did not hold formal leadership positions in their respective schools, identified their 'leadership role' as a challenge, citing the need for 'more guidance or mentoring' in their role.

I'm questioning myself about possibly how well I did and what I should or could have done that might have made the experience better for both the participants and also possibly myself. I'm wondering whether in fact I actually did enough. (AU school-based leader Bill)

If the strength of POT lies in the ability to bring theory and practice together (Donnelly, 2007) then the issue of dissemination and sharing of ideas is a major issue 
for institutions. As EN senior leader John pointed out, peer feedback is about a change of culture and that won't happen quickly. EN school-based leader Beth added 'if we are all part of the solution we can make it happen, we can improve teaching'. Clearly any shift and innovation in practice takes time thus the sustainability of such initiatives becomes a crucial question.

Sustainability was a major issue for both universities. All respondents recounted that valuable schemes had disappeared over time, fearing that without the right structures in place, POT could suffer the same fate. Australian respondents described their hopes that POT would become 'core business' and 'just part of what we do' (AU senior leader Greg). Important in this process was the need to highlight the strategic nature of the program and for it not to become 'just about compliance' (AU senior leader Don) in the way that concerned Houston (2007). One EN school-based leader expressed the views of all saying,

it's only sustainable if people get something out of it or want to carry on doing it and see the value of it... (EN school-based leader Kerry)

Whilst both sets of respondents held similar fears about sustainability the Australians focussed on its importance regarding what they did in their jobs, whereas the English focussed on the need for people to see the value of this process to engage with it. These contrasts between the hopeful and positive responses from the Australians and the more cynical and wary responses of the English may reflect aspects of the wider political culture within the respective higher education contexts. There are strong arguments to suggest that performativity and accountability are key drivers in the English educational landscape (O'Leary, 2013) and have been increasingly emphasis on these over more than two decades has led to cynicism.

\section{Limitations of the study}

In building links between findings from these two case studies and the broader context of the higher education, we note that the degree to which the issues and challenges captured through this study reflect patterns across the wider sectors that cannot be generalised. Principally, the focus was on discovery, not confirmation (Burns, 2000). Such discovery involved identifying and exploring the issues and challenges that have arisen for the participants that warrant further investigation. The challenges identified in this research provide a catalyst for follow-up investigation and raise questions for further research and informed institutional action.

\section{Implications for future leadership}

The need for academic leaders to foster shared understandings, ownership of POT processes and how they intersect with relations of power and managerial and quality assurance agendas resonates throughout our data. At its best POT offers an experience that can enhance, professionalise and support improvement in teaching and learning practices (Donnelly, 2007). However, for this to happen and become something that is meaningful to educators the process of POT needs to be led in ways that do not subvert individual agency and which ensures that learning aligns with both individual goals as well as the aspirations of the institution.

Our findings suggest the need for a collegiate and transparent leadership approach. POT must be underscored by clearly defined principles, which are shared and enacted 
through respectful and democratised academic learning and teaching leadership. Principles of ownership and mutual respect were important to most leaders in our study as were trust, confidentiality and a focus on the developmental process of POT.

Despite leaders expressing the positive potentials of linking POT to systems of rewards and recognition, tensions exist regarding why and to whom the experience of POT was disseminated beyond the participating teaching staff. This was a significant tension in the English responses and the perceived risk that this brought POT a step closer to an inspection regime that could be seen as destructive rather than constructive. Whilst it is possible to see institutional benefits and even individual benefits where the person in question welcomes such a link, this becomes more problematic when looking at this issue in more depth. Some leaders raised issues about how we might judge practice and whether this is in fact a process where making judgements is appropriate. If situated within a system of critical reflection then this becomes a two-way (or indeed multiple-way) interaction where peer support is emphasised and where the power in the relationship is shared and/or reciprocal. We note that conceptions of effective teaching in higher education are wide ranging and to some degree at least, shaped by the disciplinary context.

Given the developmental focus of the Australian programme and its confidential nature, the role of management was debated. Respondents acknowledged the challenges for school leadership in investing in the programme, supporting its implementation, whilst remaining 'light touch' in encouraging involvement. What became clear however was that the English respondents were focussed on time, workloads and accountability. Australian responses were based on developmental strategies that minimise the negative effects of management.

Findings affirm that tensions arise where POT is associated with anything punitive. Some English respondents discussed using POT to identify 'poor' practice. We argue that performance management should be seen as an entirely separate activity to POT. Only then can the trust required to engage educators in this process be developed. POT is unlikely to gain support if the outcomes of the observation can be used to condemn the person's work practice. Links of this nature would also lead to greater bureaucracy, something Knights and McCabe (2000) warned against.

Our findings signify tensions in leading POT that relate to its implicit and explicit purpose. We consider that POT should raise the profile and standing of teaching and learning within institutions. Institutions need to support the leadership of POT and demonstrate a genuine commitment to this activity through the provision of time, training and additional necessary resources. If not then the institution is open to accusations of this activity being one that is entirely based around compliance. (Shortland, 2004).

Cultural change requires time. Given that academics are the biggest resource in higher education then it is eminently sensible to nurture and support best-practice including creating opportunities to disseminate and share teaching practice, supported by sensitive and useful feedback on teaching. If educators are empowered to engage in the process of POT in ways that are meaningful then they are likely to build systems that develop their own learning and embed theory within practice (Donnelly, 2007; Shortland, 2004). As Shortland (2004) reported, academics do adapt processes for 
their own support if left to get on with it. A meaningful process becomes sustainable as people wish to be a part of it.

POT in Australia and the wider UK has had inconsistent success and historically been largely unsupported by 'culture and policy' (Devlin and James, 2008; Blackmore, 2005). For POT to succeed, it is imperative for leaders to be empathically human rather than punitively hierarchical so that they may function in collaborative and cooperative ways. Quinlan (2011) identifies that the systems of higher education, in the US, UK and Australia, are 'contested and conflicted' (p. 40) and that authentic leadership must be based on 'values and ethics' (p. 37). She suggests that managerialist agendas, and the increasing emphasis on economic outputs and returns, is counter intuitive to the values upheld by the academy and the ethos of the university community. Quinlan highlights the tensions inherent within the dominant discourse of quality assurance for managerialist purposes and how this adversely intersects with developmental POT. Our findings further highlight the nexus between discourse and power, and evidence how 'institutions and our roles within them are in frequent measure defined by such particular language use' (Fairclough 1989, p. 5).

\section{Conclusion}

In their analysis of POT Hammersley-Fletcher and Orsmond (2004) argue that time will tell if such systems are effective in shifting and improving teaching practices, but that the degree to which such practices are meaningful is contingent on the conditions of the workplace. Such conditions include the particular philosophical approach adopted by learning and teaching leadership. In a recent study which investigated the efficacy of a distributed leadership approach to POT it was identified that a key challenge for universities is 'to ensure that evidence-based leadership approaches are developed and implemented within a framework that invests in leadership building capacity to create the conditions in which leaders can flourish and grow to ensure continuous improvement for all' (Wingrove, Clarke, and Chester, 2015). In seeking to contribute to this knowledge base, our findings highlight the importance of creating a culture through respectful collegiate leadership in which POT is enacted as developmental and emancipatory.

This aspiration sits within the wider context whereby the quest for quality, and accountability shapes the higher education discourses. O'Leary (2013), draws upon the work of Robson (1998) to identify that new managerialsim holds as a 'central tenant...the view that workers could no longer be trusted to do their jobs efficiently and effectively' (p. 696). Within this paradigm, educators are positioned, empowered and ultimately disempowered within a culture which privileges performance and productivity.

Charged with the responsibility to measure productivity and performance, in England POT has emerged 'as an important means of gathering evidence for colleges' quality systems and preparing for Ofstead inspections' (O'Leary, 2013). Similarly in Australia, quality assurance and measurement imperatives occupy a prominent place in the higher education discourses, with performativity through continuous improvement in learning and teaching now central to the very practice of learning and teaching itself (Shah \& Jarzabkowski, 2013). Yet differences exist in the enactment of POT. In England, POT for the purpose of reviewing teaching practice, 'has gained a firm stronghold (Sachs \& Parsells, 2014, p. 2). By contrast in Australia, whilst there is 
evidence of developmental POT approaches being employed, POT for review purposes has not been systematically implemented (Klopper \& Drew, 2015).

Developmental POT is challenging to implement and grow. Our leaders identified that POT must be underpinned by the core values of respect, academic scholarship, freedom and integrity. Such values resonate with the principles as proposed by Barnard, Croft, Irons, Cuffe and Bandara (2011) who identify that beyond learning and teaching expertise and the provision of resources it is also vital when seeking to embed POT to establish the cultural conditions which: 'establish a supportive and constructive collegial environment; provide experiences that affirm educational excellence; develop a culture that values scholarship of teaching; promote selfassessment, reflection and personal growth; and enhances teaching and learning based on evidence and constructive support' (Barnard, et al. 2011, p. 438).

In his analysis of the challenges inherent in effectively implementing Collaborative Peer Supported Review of Teaching, Gosling (2014) notes that 'any intervention aimed at enhancing teaching and learning ...cannot be separated from wider contextual issues relating to organisational structures and culture' (p.24). In acknowledging the value of developmental POT, which he terms and conceptualises as Peer Supported Review, Gosling (2014) acknowledges that 'pre-existing organisational culture has a strong influence on the 'absorptive capacity' of individuals to benefit from opportunities for professional learning' (p.24).

A key challenge facing leaders of teaching and learning in higher education is to ensure that leading such change is supported through policy, action and culture. As we have explored, the desired institutional cultural milieu is one that foregrounds agency and trust. As Gosling (2014) identifies, core to the challenges in doing so is to negotiate change in ways which cultivate the learning organization. Sustainable and systematic uptake of educational innovations in higher education is also predicated upon the engagement of all stakeholders within the academic hierarchy (Barnard, Nash, Mcevoy, Shannon, Waters, Rochester and Bolt, 2014).

Whilst POT can become an enabler of creativity and innovation, accountability agendas mitigate against its developmental capacity (O'Leary, 2013). If academic leadership can challenge, disrupt and reposition these performance driven accountability agendas to foster a respectful, collegiate culture of POT, then POT for developmental learning about teaching can be successfully introduced and we hope thrive, for the benefit of all.

\section{References}

Barnard, A., Croft, W., Irons, R., Cuffe, N. and Bandara W. R. P. (2011). Peer partnership to enhance scholarship of teaching: A case study. Higher Education Research and Development, 30(4), 435-448

Bell, A. and Mladenovic, R. (2008). The benefits of peer observation of teaching for tutor development. Higher Education 55, 735-752.

Bell, M. (2005). Peer Observation Partnerships in Higher Education. Milperra, 


\section{N.S.W: HERDSA.}

Blackmore, J. (2005). A critical evaluation of peer review via teaching observation within higher education. International Journal of Educational Management 19 (3), $218-232$.

Boud, D. (2001). Introduction in making the move to peer learning. In Learning in Higher Education: Learning From and with Each Other. London: Kogan Page Ltd.

Braun, V. and Clarke, V. (2006). Using thematic analysis in psychology. Qualitative Research in Psychology 3 (2), 77-101.

Carroll, C. and O'Loughlin, D. (2014). Peer observation of teaching: enhancing academic engagement for new participants. Innovations in Education and Teaching International 51 (4), 446-456

Chester, A. (2012). Peer partnerships in teaching: Evaluation of a voluntary model of professional development in tertiary education. Journal of the Scholarship of Teaching and Learning 12 (2), 94 - 108.

Donnelly, J. (2007). International Human Rights (3rd edn) Westview Press: Colorado.

Fairclough, N. (1989). Language and Power. London: Longman.

Gosling, D. (2002). Models of Peer Observation of Teaching. Paper presented at LTSN Generic Centre Learning and Teaching Support Network, York. August.

Gosling, D. (2005). Peer observation of teaching. SEDA Paper 118. London: Staff and Educational Development Association Ltd.

Gosling, D. (2014). Collaborative peer-supported review of teaching. In Peer Review of Learning and Teaching in Higher Education, International Perspectives, edited by J. Sachs \& M. Parsell, 13-31. Netherlands: Springer.

Hammersley-Fletcher, L. and Orsmond, P. (2004). Evaluating our peers: Is peer observation a meaningful process? Studies in Higher Education 29 (4): 489-503.

Hanson, J. (2013). Educational developers as researchers: the contribution of insider research to enhancing understanding of role, identity and practice. Innovations in Education and Teaching International 50 (4): 388-398.

Henard, F. and Roseveare, D. (2012). Fostering quality teaching in Higher Education: policies and practices. An IMHE guide for Higher Education Institutions. OECD: Institutional Management in Higher Education. Accessed 28 October 2014 http://www.oecd.org/edu/imhe/QT\%20policies\%20and\%20practices.pdf

Hodder, I. (1994). The Interpretation of Documents and Material Culture. In Handbook of Qualitative Research, edited by N.K. Denzin and Y.S. Lincoln. Thousand Oaks, CA and London: Sage. 
Houston, D.J. (2007). TQM and higher education: a critical systems perspective on fitness for purpose. Quality in Higher Education 1, 3-17.

Klopper, C. and Drew, S. (Eds.) (2015). Teaching for learning and learning for teaching. Rotterdam, AW: Sense Publishers

Knights, D. and McCabe, D. (2000). Ain't Misbehavin'? Opportunities for Resistance Under New Forms of 'Quality' Management. Sociology 34, 421-36.

O'Leary, M. (2013). Surveillance, performativity and normalised practice: the use and impact of graded lesson observations in further education colleges. Journal of Further and Higher Education, 37 (5), 694-714.

Lomas, L. and Nicholls, G. (2005). Enhancing teaching quality through peer review of teaching. Quality In Higher Education 11 (2), 137-149.

Patton, M Q. (2002). Qualitative Research and Evaluation Methods. Thousand Oaks, CA: Sage Publications.

Peel, D. (2005). Peer observation as a transformatory tool? Teaching in Higher Education 10(4), 489- 504.

Quinlan, K M. (2011). Developing the Whole Student: Leading Higher Education Initiatives. London: Leadership Foundation for Higher Education.

Sachs , J. and Parsell, M. (2014) The place of Peer Review in Learning and Teaching. In Peer Review of Learning and Teaching in Higher Education, International Perspectives, edited by J. Sachs \& M. Parsell, 13-31. Netherlands: Springer.

Shah, M. and Jarzabkowski, L. (2013). The Australian higher education quality assurance framework, Perspectives: Policy and Practice in Higher Education, 17 (3), 96-106.

Shortland, S. (2004). Peer observation: a tool for staff development or compliance? Journal of Further and Higher Education 28 (2), 219-228.

Skelton, A. (2012). Colonised by quality? Teacher identities in a research-led institution. British Journal of Sociology of Education, 33(6), 793-811.

Speck, M. (1996). Best practice in professional development for sustained educational change. ERS Spectrum, 33-41.

Trowler, P.R. and Knight, P.T.. (2000). Coming to know in Higher Education: Theorising faculty entry to new work contexts. Higher Education Research \& Development 19(1): 27-42.

Wingrove, D., Clarke, A. and Chester, A. (2015). Distributing leadership for sustainable peer feedback on tertiary teaching. Journal of University Teaching and Learning 12 (3), article 8. 